$\begin{array}{cc}\text { ACADEMIA ROMÂNĂ } & \text { Rev. Roum. Chim., } \\ \text { 2019, 64(9), 755-761 } & \text { Devue Roumaine de Chimie } \\ \text { http://web.icf.ro/rrch/ } & \text { DOI: 10.33224/rrch.2019.64.9.02 }\end{array}$

\title{
EVALUATING OPTIMUM CONDITIONS FOR FATIGUE LIFE OF NR-BASED RUBBER COMPOUNDS USING THE TAGUCHI METHOD
}

\author{
Fereshteh MOTIEE, ${ }^{*}$ a and Zohreh GHAZI TABATABAEI ${ }^{\mathrm{b}}$ \\ ${ }^{a}$ Department of Chemistry, Tehran North Branch, Islamic Azad University, Tehran, Iran \\ ${ }^{\mathrm{b}}$ Department of Chemistry, Ahar Branch, Islamic Azad University, Ahar, Iran
}

In the present work, four relevant factors, temperature, time, humidity, and storage condition (Oxygen-flow rate) were selected, and to monitor the extent of degradation, the effect of each factor was studied at three different levels on the ozone resistant and fatigue life time of rubber compounds. The optimal combination of physical parameters based on the Taguchi protocol and maximum fatigue life was obtained. Comparison between the confirmation run and prediction from optimal factor settings illustrate that the Taguchi parameter design is very practicable in optimizing the factors influencing aging of natural rubber based compounds. Taguchi method stresses the importance of studying response variation using the signal-to-noise $(\mathrm{S} / \mathrm{N})$ ratio, resulting in minimization of quality characteristic variations due to uncontrollable parameters. Therefore, $\mathrm{S} / \mathrm{N}$ ratio and ANOVA were applied to investigate a set of parameters. The optimum conditions implicated for maximum ozone resistance and fatigue life of aged rubber compounds based on NR were time: one day; temperature: $25^{\circ} \mathrm{C}$; storage condition: air, and humidity: $65 \%$.

\section{INTRODUCTION}

Natural Rubber (NR) is chemically based on cis 1,4-polyisoprene, which is characterized by well elastic properties, flexibility and damping behavior and the inimitable mechanical properties of NR are due to the highly stereo regular microstructures resulting from its high molecular weight. ${ }^{1}$ These properties fall short in special applications such as oil resistance, air permeability, ozone resistance, compression set, and thermal aging resistance. ${ }^{2}$ Its resistance to heat, oxygen, and ozone is poor due to the presence of a high number of double bonds in its chemical structure. ${ }^{3}$ Thus, this necessitates further inquiry into natural rubber degradation.

Degradation of natural rubber can be ensued by a variety of environmental factors including raised temperature, humidity, swelling, impurities, mechanical load, irradiation, and chemicals. In the presence of atmospheric oxygen, the useful lifetime of many polymer products is limited by oxidative reactions. ${ }^{4}$ Radical attack of the elastomer chain causes chain scission, crosslink formation, and crosslink breakage. Thus, change in properties of elastomers with aging depends on the extent of such reaction. ${ }^{5}$ 
According to the experimental results (in 2005), vulcanizates cured with the binary systems exhibit better curing efficiencies and thermal aging resistances compared to those of the single systems. ${ }^{6}$ $\mathrm{NR}$, when properly compound with either suitable wax or antioxidants, will have ozone resistance in the same class as or far better than numerous engineered rubbers. ${ }^{7}$ Other researchers have also described the impacts of temperature and ecological components on the performance of elastomers and various degradation reactions including their mechanisms. ${ }^{8-12}$ Thermal degradation and ageing properties of individual lattices and their blends were investigated with special reference to blend ratio and vulcanization techniques. ${ }^{13-22}$

These days the objective is to achieve the best results within the shortest time, with negligible contamination and generation of minimal residue or waste. Taguchi's protocol is a unique and powerful optimization discipline that allows optimization with least number of experiments. Therefore, an experimental validation is run utilizing the anticipated ideal levels for the control parameters under study and applicability of the design method. ${ }^{23-25}$

Dar Yuan Chang et al. ${ }^{26}$ studied about vacuum casting experiments via Taguchi's method to derive the optimal parameter choices on ABS plastic vacuum casting using a silicone rubber mold. The factor that influences pouring characteristics maximally is the mold vacuuming time. Ku Zarina $\mathrm{Ku}$ Ahmad et al. ${ }^{27}$ investigated the optimization of tensile Property of Epoxy/ Nanoclay /MWNT Nano composites using the Taguchi method. The confirmation experiment obtained from Taguchi analysis achieved 57\% improvement in tensile strength. Der Ho Wu et al., in $2010,{ }^{28}$ examined the Taguchi Method in fabricating the MWCNT/ Natural rubber vibration isolator. It has been found that the MWCNT/NR isolator manufactured using this procedure can obtain a higher damping proportion and better vibration isolation contrasted to pure natural rubber isolator.

In 2011, fatigue and mechanical properties of Nylon 66/Polyester (Ny 66/PET) hybrid cords, Ny 66 and polyester reference cords used in tire industry were studied. It was found that the most effective factor was cable twist level through which better fatigue resistance for hybrid cords can be obtained. ${ }^{29} \mathrm{R}$. Manshaie et al. ${ }^{30}$ reported the use of factorial outline in determination of physicomechanical properties of NR/SBR alloy cured by sulfur curing system. The result demonstrated that use of factorial outline significantly reduces research and development costs by decreasing the number of experimental configurations to study. M. Hafezi et $a l .{ }^{31}$ applied the Taguchi method to determine the optimum level of curing system (sulfur, MBTS, and CBS) in a NBR/PVC blend. A fixed master batch formulation of NBR/PVC was used and the effect of the curing system was studied on the physic-mechanical properties of NBR/PVC blend, such as tensile strength (TS) and elongation-at-break (EB) before and after aging, hardness, and abrasion.

This work is focused on the optimization aging conditions of NR-based rubber compounds [time, temperature, humidity, storage condition (Oxygenflow rate)] at three different levels for improving fatigue life using partial factorial design of orthogonal array of the Taguchi procedure. The optimum condition that was suggested by ANOVA method was prepared and the experimental data were compared with theoretical data.

\section{EXPERIMENTAL}

\section{Materials}

The type of NR employed was STR 20 graded Thaihua Company, Thailand. The rubber compounds formulation for tire tread is given in Table I. As for the majority of cases, tire compounds are unsaturated polymers that have been fortified with carbon black, and are vulcanized by sulfur system, the formulated mixes were blended on a two-roll mill in which the blending operation time and cutting operation were checked. The temperature range for blending was 70$75^{\circ} \mathrm{C}$. The request and average time for blending was as follows: 12 Min- Mastication, 20 Min- Addition of filler, 10 Min- Addition of powdered materials and 10 MinAddition of curatives (mill temperature $65^{\circ} \mathrm{C}$ ).

The molding conditions of rubber blends were determined from data obtained by a (Hiwa) rheometer at $160^{\circ} \mathrm{C}$ temperature for duration of 25 minutes. The remaining mixes were sheeted out to around $2 \mathrm{~mm}$ thickness.

\section{Taguchi methodology}

The Taguchi method has generally been accepted to optimize the design parameters because this systematic approach can significantly produce high quality products by minimizing the overall testing time and the experimental costs. The most important stage in the Taguchi method is to select a proper Orthogonal Array (OA) which depends on the number of factors, interactions and levels needed..$^{31,32}$

The initial step is to determine the different agents that have critical impact on the aging of rubber compound. Based on the recent investigation, four factors (time, temperature, humidity and storage conditions) were selected for the present study (Table 2). . $^{33,34}$

The following step was to outline the matrix experiment and characterize the data investigation method. The appropriate OAs for control parameters to fit a suitable survey was chosen. 
Table 1

The compound formulation

\begin{tabular}{lccc}
\hline & Components & phr $^{\mathbf{a}}$ & Company \\
\hline NR & Mooney viscosity $=94.5$ & 100 & Thaihua, Tailand \\
carbon black N-330 & Iodine number=82 & 38 & Pars Tire, Iran \\
Oil (aromatic) & & 5 & Iran \\
Zinc oxide & Assay $=92 \%$ & 6 & Shekoieh, Iran \\
Stearic acid(PLMAC 1600) & Assay=95\% & 5 & Acid Chemie, Malaysia \\
Anti-oxidant HB & & 1.5 & Nanjing, Chaina \\
IPPD ${ }^{\text {b }(P i l f i x ~ 13) ~}$ & & 1 & Nacil, India \\
Rio wax(Anti Lux645) & & 2 & Rhien Chemie, Germany \\
Sulfur & Assay=99\% & 3.75 & Tesduck, Iran \\
CBS & & 1.2 & LG / Lanxess, Belgium \\
\hline
\end{tabular}

${ }^{a}$ phr: part hundred in rubber

b IPPD: N-isopropyl-N'-phenyl-p-phenylene diamine (antioxidant, antiozonant)

${ }^{\mathrm{c}} \mathrm{CBS}$ : N-Cyclohexyl-2-benzothiazole sulfonamide (vulcanization accelerator)

Table 2

Parameters, codes, and level values used for orthogonal array

\begin{tabular}{ccccc}
\hline Code & Factor & Level 1 & Level 2 & Level 3 \\
\hline a & Time(day) & 1 & 7 & 14 \\
b & Temperature $\left({ }^{\circ} \mathrm{C}\right)$ & 5 & 25 & 45 \\
c & Storage condition & $\begin{array}{c}\mathrm{O}_{2} \\
(5 \mathrm{ml} / \mathrm{min})^{*}\end{array}$ & Air & $\begin{array}{c}\mathrm{O}_{2} \\
(10 \mathrm{ml} / \mathrm{min})\end{array}$ \\
d & Humidity $(\%)$ & 45 & 65 & 85 \\
\hline
\end{tabular}

* Oxygen-flow rate

Table 3

The $\mathrm{L}_{9}$ Orthogonal Array Layout

\begin{tabular}{ccccc}
\hline Run No. & Time(day) & $\begin{array}{c}\text { Temperature } \\
\left({ }^{\circ} \mathbf{C}\right)\end{array}$ & Storage condition & Humidity (\%) \\
\hline 1 & 1 & 5 & $\mathrm{O}_{2}(5 \mathrm{~mL} / \mathrm{min})$ & 45 \\
2 & 1 & 25 & Air & 65 \\
3 & 1 & 45 & $\mathrm{O}_{2}(10 \mathrm{~mL} / \mathrm{min})$ & 85 \\
4 & 7 & 5 & Air & 85 \\
5 & 7 & 25 & $\mathrm{O}_{2}(10 \mathrm{~mL} / \mathrm{min})$ & 45 \\
6 & 7 & 45 & $\mathrm{O}_{2}(5 \mathrm{~mL} / \mathrm{min})$ & 65 \\
7 & 14 & 5 & $\mathrm{O}_{2}(10 \mathrm{~mL} / \mathrm{min})$ & 65 \\
8 & 14 & 25 & $\mathrm{O}_{2}(5 \mathrm{ml} / \mathrm{min})$ & 85 \\
9 & 14 & 45 & Air & 45 \\
\hline
\end{tabular}

In the present case, three levels for factor varieties were considered and the size of the experimentation was represented by symbolic arrays $\mathrm{L}_{9}$ (which indicates nine experimental trails). Four variables with three levels were utilized and depicted in Tables 2 and 3, respectively. In the Taguchi method, a loss function, signal-to- noise ratio, is defined to calculate the deviation between the experimental value and the desired value. Usually there are three classes of the performance characteristics in the analysis of the $\mathrm{S} / \mathrm{N}$ ratio, smaller is better, larger is better, and nominal is the best characteristic. $^{35-38}$ The acquired experimental data were processed with "bigger is better" quality attributes for 
determination of optimum conditions of Time(day), Temperature $\left({ }^{\circ} \mathrm{C}\right)$, Storage condition and Humidity (\%), according to different level of four factors influencing aging of NR. A statistical analysis of variance (ANOVA) can be used to present the impact of procedure parameters on the age life of rubber compounds. In this way, optimum levels of procedure parameters can be anticipated. ${ }^{37}$

\section{Chemical Analysis}

The uncured rubber specimens were aged at different conditions according to Table 2 . The molding conditions of rubber blends were determined by using a Moving Die Rheometer (MDR) at $160^{\circ} \mathrm{C}$ temperature for duration of 25 min. Before the tests, all nine samples (aged at different conditions) were vulcanized in hot press by means of standard dies in accordance with ASTM D5289 standard, and then the required samples for the physical tests were prepared. The rheometer properties, ozone resistance tests were taken according to ASTM 5289 and 1149 and fatigue tests are performed on flat dumbbell specimens under non-relaxing conditions at large strain levels by ISO 6943. The results determined by this research are discussed with respect to the fatigue life of rubber compounds (Table 3 ).

\section{RESULTS}

\section{Conceptual $S / N$ ratio approach}

The Taguchi method used the signal to noise $(\mathrm{S} / \mathrm{N})$ proportion approach to measure the quality characteristic. The $\mathrm{S} / \mathrm{N}$ ratio is quoted in $\mathrm{dBi}$ units and can be defined as follows:

$$
\eta=-10 \log \text { (M.S.D.) }
$$

where $\eta$ is the $\mathrm{S} / \mathrm{N}$ ratio and M.S.D. is the mean square deviation for the output characteristic. ${ }^{37}$

Since the main objective of this report is to increase fatigue life by optimizing the factors influencing the time of life of rubber compounds, thus, the "bigger-the-better" quality characteristic is utilized in this study. The M.S.D. for the bigger the better quality characteristic can be expressed as:

$$
\text { M.S.D. }=\frac{1}{n}\left(\sum_{i=1}^{n} \frac{1}{y^{\frac{2}{i}}}\right)
$$

where $\mathrm{y}_{\mathrm{i}}$ is the observed data and $n$ is the total number of data points. Because $-\log$ is a monotone increasing function, it implies that we should minimize the $\mathrm{S} / \mathrm{N}$ value. ${ }^{37}$ Hence, $\mathrm{S} / \mathrm{N}$ values are calculated by exploiting equations (1) and (2), and results are shown in Table 4.

By averaging the $\mathrm{S} / \mathrm{N}$ ratios of all experiments at each level for each factor, the response of each factor to its individual level has been computed. By averaging the amount of $\mathrm{S} / \mathrm{N}$ proportion at various levels, the $\mathrm{S} / \mathrm{N}$ proportion for a single factor can be evaluated. For instance, by averaging the $\mathrm{S} / \mathrm{N}$ ratios for experiments 1,4 , and 7 , the mean $\mathrm{S} / \mathrm{N}$ proportion for temperature at level $1 \mathrm{can}$ be computed. The mean $\mathrm{S} / \mathrm{N}$ proportion for every factor at various levels is computed similarly. ${ }^{38}$ The fatigue life response table for each procedure parameters at the levels of 1,2 , and 3 was made by using the $\mathrm{S} / \mathrm{N}$ proportion (Table 5 ). In addition, $\mathrm{S} / \mathrm{N}$ ratio was calculated for four parameters (Table 6).

In finding the optimum levels of the four aforementioned parameters, Figure 1 is drawn using the $\mathrm{S} / \mathrm{N}$ response table for fatigue life of rubber compounds based on NR. It is additionally seen from Figure 1 that the maximum $\mathrm{S} / \mathrm{N}$ response value at each level exhibited the most ozone resistance.

Table 4

\begin{tabular}{|c|c|c|c|}
\hline Run No. & $\begin{array}{l}\left(R_{1}\right) \text { Fatigue Life } \\
\text { (cycl/sec) }\end{array}$ & $\begin{array}{l}\left(\mathbf{R}_{2}\right) \text { Fatigue Life } \\
\text { (cycl/sec) }\end{array}$ & $\mathrm{S} / \mathrm{N}$ ratio \\
\hline 1 & 52734 & 48796 & 70 \\
\hline 2 & 74099 & 69011 & 70 \\
\hline 3 & 63000 & 64916 & 70 \\
\hline 4 & 17700 & 17684 & 69.74 \\
\hline 5 & 15625 & 16199 & 70 \\
\hline 6 & 23450 & 23256 & 69.92 \\
\hline 7 & 3041 & 3033 & 69.01 \\
\hline 8 & 2866 & 2842 & 68.15 \\
\hline 9 & 4404 & 3882 & 68.67 \\
\hline
\end{tabular}

Experimental results for Fatigue life and $\mathrm{S} / \mathrm{N}$ ratio 


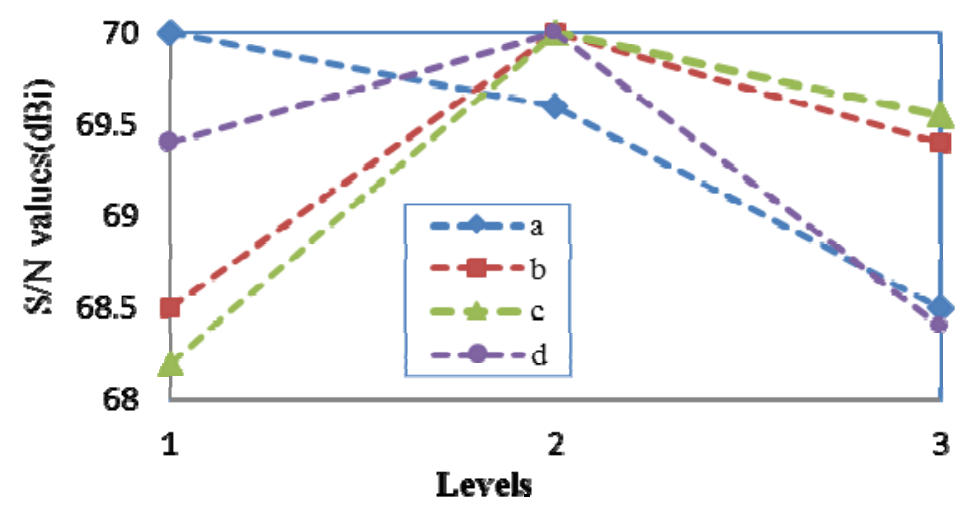

Fig. 1 - Plots of control parameters effects for the fatigue life.

Table 5

Response values table

\begin{tabular}{ccccc}
\hline Process parameter & Time(day) & $\begin{array}{c}\text { Temperature } \\
\left({ }^{\circ} \mathbf{C}\right)\end{array}$ & Storage condition & $\begin{array}{c}\text { Humidity } \\
(\mathbf{\%})\end{array}$ \\
\hline Values & 62092 & 30106 & 31130 & 32648 \\
Levels & 1 & 2 & 2 & 2 \\
\hline
\end{tabular}

Table 6

$\mathrm{S} / \mathrm{N}$ Response values table

\begin{tabular}{ccccc}
\hline Process parameter & Time(day) & $\begin{array}{c}\text { Temperature } \\
\left({ }^{\circ} \mathbf{C}\right)\end{array}$ & Storage condition & $\begin{array}{c}\text { Humidity } \\
(\%)\end{array}$ \\
\hline Values & 70 & 70 & 70 & 70 \\
Levels & 1 & 2 & 2 & 2 \\
\hline
\end{tabular}

Under respective columns time (day), temperature $\left({ }^{\circ} \mathrm{C}\right)$, storage condition and humidity, you have put values and levels.

\section{Analysis of Variance}

In the Taguchi protocol, analysis of variance (ANOVA) is utilized to analyze the result of OA experiments and to determine the amount of variation each factor has contributed. Structured from the computed proportion $(\mathrm{F})$, it can be alluded that all variables and interactions considered in the experimental design are statistically noteworthy effective at $95 \%$ confidence level, showing that the variability of experimental data is clarified as far as huge impacts are concerned.

By examining the principle impacts of each of the factors, the general patterns of their impact toward the procedure can be characterized. The attributes can be controlled such that a lower or a higher value in a specific impacting factor creates the favored result. In this manner, the level of factors leading to the best possible results can be estimated.

In this study, the aim of the analysis of variance is to assess the impact and relative significance of the four control factors on the fatigue life of rubber compounds based on NR. Identifying the efficacy of control factors becomes increasingly easier due to the investigation results. ANOVA has been established based on Sum of Squares (SS), Degree of Freedom (D), Variance (V), and percentage of contribution to the total variation $(\mathrm{P})$, which can be computed as follows. ${ }^{16,38,39}$

The total sum of squared deviation $\mathrm{SS}_{\mathrm{T}}$ from the total mean $\mathrm{S} / \mathrm{N}$ ratio can be calculated as follows:

$$
S S_{T}=\sum_{i}^{m} n_{i}^{2}-\frac{1}{m}\left[\sum_{i=1}^{m} n_{i}\right]^{2}
$$

where $m$ is the number of experiments in the orthogonal array and $\mathrm{n}_{\mathrm{i}}$ is the $\mathrm{S} / \mathrm{N}$ ratio at the $i$ th experiment. 
Table 7

\begin{tabular}{|c|c|c|c|c|}
\hline \multicolumn{1}{|c|}{} & \multicolumn{3}{|c|}{ ANOVA results } \\
\cline { 2 - 5 } & Time(day) & Temperature $\left(\mathbf{~}^{\circ} \mathbf{C}\right)$ & Storage condition & $\begin{array}{c}\text { Humidity } \\
\mathbf{( \% )}\end{array}$ \\
\hline Sum of sq. & 0.431 & 0.152 & 0.143 & 0.139 \\
\hline Variance (V) & 0.215 & 0.074 & 0.69 & 0.069 \\
\hline F ratio (F) & 1721.31 & 25.85 & 14.18 & 38.14 \\
\hline Percent (\%) & 50.15 & 16.32 & 12.74 & 20.79 \\
\hline
\end{tabular}

The percentage contribution $\rho$ can be calculated as follows:

$$
\rho=\frac{S S_{d}}{S S_{T}}
$$

where $S S_{d}$ is the sum of squared deviations and can be calculated as follows: ${ }^{40}$

$$
S S_{d}=\sum_{j=1}^{t} \frac{\left(S_{n j}\right)^{2}}{t}-\frac{1}{m}\left(\sum_{i=1}^{m} n_{j}\right)
$$

where $S S_{d}$ denotes the sum of squares for the experimental factors, $d$ represents one of the experimental factors, $j$ is the level number of this specific factor $d$, $\mathrm{t}$ is the repetition of each level of the factor $d$, and $S_{n j}$ is the sum of the $\mathrm{S} / \mathrm{N}$ ratio involving this factor and level $j .{ }^{38}$ ANOVA results are shown in Table 7.

It can be observed from Table $5 \& 7$ that Time (day), Temperature $\left({ }^{\circ} \mathrm{C}\right)$, Storage condition and Humidity (\%) influence fatigue life by $50.15 \%$, $16.32 \%, 12.74 \%$, and $20.79 \%$, respectively. It can be observed that time is the most significant factor influencing fatigue strength of rubber compound. Humidity and temperature are the next most important factors in the aging of NR-based rubber compounds. Storage conditions indicated minimum effect among the factors studied with the assigned variance of values.

\section{Determining maximum fatigue life}

According to the capability of the Taguchi Parameter Design in predicting the influence of control factors on response, this study was conducted using an additional model, which refers to the sum of the individual factor effects without interactions or cross terms. Substituting appropriate values for factors in the equation is the way for finding predicted values. The factors plot is incapable of easily showing the applicability of the additive. However, if the predictive equation is successful in predicting the results of different combinations of control factors, then it is obvious that the additive equation applies and the interactions of control factors are low. This is the main purpose of the verification experiment. Thus, in this situation $Y_{\text {predictive }}$ was determined using optimal levels of parameters in Table 5 (Response values table).

$$
\boldsymbol{Y}_{\text {predictive }}=Y_{\text {ave }}+\left(\overline{a_{1}}-Y_{\text {ave }}\right)+\left(\overline{b_{2}}-Y_{\text {ave }}\right)+\left(\overline{c_{2}}-Y_{\text {ave }}\right)+\left(\overline{d_{2}}-Y_{\text {ave }}\right)
$$$$
Y_{\text {ave. }}=\frac{\Sigma y_{i}}{n_{i}}=28141
$$$$
Y_{\text {predictive }}=71608.6
$$

where $Y_{\text {ave }}$ is the overall averages response for the entire orthogonal array, and $\boldsymbol{a}_{1} \boldsymbol{b}_{2} \boldsymbol{c}_{2} \boldsymbol{d}_{2}$ are the response averages for factors $a, b, c$, and $d$, respectively. Confirming validity of the combination of the optimum control factors by illustrating the predictability and reproducibility of the optimum parameter setting is the goal of the verification experiment. Therefore, similarity of

the verification result and predicted result can be evidence of success for the additive model. This result obtained from the predictive equation is compatible with the second experiment with $0.074 \%$ error in Table 4.

\section{CONCLUSIONS}

Based on the results obtained from this work, the following conclusion can be drawn:

The effect of four independent parameters on ozone resistance and fatigue life of aged NR-based rubber compounds were evaluated; 
The Taguchi orthogonal array design was selected and 9 specimens were prepared and tested based on designed levels for each response;

The obtained optimal conditions for aged sample were validated by performing the experiments with the assigned levels;

Storage time is the most influential factor on the fatigue life among the four controllable factors. Aside from this, the average value of $\mathrm{S} / \mathrm{N}$ ratios of the time was 70 and its percentage contribution was $50.15 \%$. It should be noted that the mechanical properties of rubber will drop dramatically with increasing storage time from one day to two weeks;

Humidity was the second most influential factor on fatigue life and ozone resistance among the four other factors, and its percentage contribution was $20.79 \%$;

Temperature was the third most influential parameter among the four controllable factors, and its percentage contribution was $16.32 \%$;

So the properties of the samples vary with changes in these factors.

Acknowledgements. The authors would like to express their sincere appreciation to Dr. Fariba Tadayon for her suggestions during this study. Also, the Iran Rubber Industries Research Institute is highly acknowledged for their financial support.

\section{REFERENCES}

1. V. Rao and J. Johns, J. Appl. Polymer Sci., 2008, 107, 2217-2223.

2. H.-T. Chiu, W.-C. Li and P.-A. Tsai, Polymer - Plastics Techn. Eng., 2006, 45, 845-855.

3. A. S. Sirqueira and B. G. Soares, J. Appl. Polymer Sci., 2002, 83, 2892-2900.

4. A. R. Azura and A. G. Thomas, in V. A. Coveney (Ed.) "Elastomers and Components", Woodhead Publishing, Cambridge, UK, 2006, p. 27-38.

5. J. Diez, R. Bellas, C. Ramírez and A. Rodríguez, J. Appl. Polymer Sci., 2010, 118, 566-573.

6. S.-S. Choi, D.-H. Han, S.-W. Ko and H. S. Lee, Bull. Korean Chem. Soc. (BKCS), 2005, 26, 1853-1855.

7. V. Vinod, S. Varghese and B. Kuriakose, Polymer Degradation and Stability, 2002, 75, 405-412.

8. A. Arockiasamy, H. Toghiani, D. Oglesby, M. F. Horstemeyer, J. L. Bouvard and R. L. King, J. Thermal Analysi and Calorimetry, 2012, 111, 535-542.

9. D. J. Burlett, J. Thermal Analysis and Calorimetry, 2004, 75, 531-544.

10. E. E. Kwon and M. J. Castaldi, Environ. Sci. Techn., 2012, 46, 12921-12926.

11. W. V. Mars and A. Fatemi, Rubber Chem. Techn., 2004, 77, 391-412.

12. E. E. Kwon and M. J. Castaldi, Environ. Sci. Techn., 2008, 42, 2175-2180.
13. S.-S. Choi, J. Appl. Polymer Sci., 2000, 75, 1378-1384.

14. F. Findik, R. Yilmaz and T. Koksal, Materials and Design, 2004, 25, 269-276.

15. R. Stephen, S. Jose, K. Joseph, S. Thomas and Z. Oommen, Polymer Degradation and Stability, 2006, 91, 17171725.

16. P. Sae-oui, C. Sirisinha and K. Hatthapanit, Express Polymer Lett., 2007, 1, 8-14.

17. H. Oktem, T. Erzurumlu and I. Uzman, Materials and Design, 2007, 28, 1271-1278.

18. S. Taghvaei-Ganjali, F. Motiee and F. Fotoohi, Rubber Chem. Techn., 2008, 81, 297-317.

19. N. Rattanasom and S. Prasertsri, Polymer Testing, 2012, 31, 645-653.

20. Y. S. Wang, Z. B. Cui, Q. Liu and S. S. Jiang, Advanced Materials Research, 2013, 683, 51-58.

21. E. V. Bystritskaya, T. V. Monakhova and V. B. Ivanov, Polymer Testing, 2013, 32, 197-201.

22. F. Motiee, S. Taghvaei Ganjali and M. Malekzadeh, Int. J. Ind. Chem., 2013, 4, 1-8.

23. P. Woolf (Ed.) "The Michigan Chemical Process Dynamics and Controls Open Text Book", citeulikearticle-id:6771316; 2007.

24. F. Tadayon and N. Lahiji, Int. J. Acad. Research., 2011, 3, 385-390

25. B. S. Reddy, J. S. Kumar, K. V. K. Reddy and A. A. Kumari, Int. J. Appl. Eng. Research., 2009, 4, 1169-1175.

26. D. Y. Chang and C. S. Deng, Advanced Materials Research., 2011, 201, 1668-1676.

27. K. Z. Ku Ahmad, A. Haji Sahrim, M. A. Tarawneh and P. R. Apte, Advanced Materials Research, 2012, 428, 3-9.

28. D. H. Wu and H. H. Tsai, Advanced Materials Research, 2010, 156, 1730-1738.

29. G. Milani, A. Galanti, C. Cardelli, F. Milani and A. Cardelli, Rubber Chem. Techn., 2015, 88, 482-501.

30. R. Manshaie, J. Elastomers and Plastics, 2009, 41, 543553.

31. M. Hafezi, S. N. Khorasani and F. Ziaei, J. Appl. Polymer Sci., 2006, 102, 5358-5362.

32. H. Ghanadzadeh Gilani, K. Ghanadzadeh Samper and R. Khodaparast Haghi, "Advanced Process Control and Simulation for Chemical Engineers", Apple Academic Press, 2013.

33. H-J. Christ, J. Procedia Eng., 2013, 55, $181-190$.

34. J. Norambuena-Contreras, E. Silva-Robles, I. GonzalezTorre, Y. Saravia-Montero, J. Cleaner Production, 2017, 145, 85-97.

35. M. Kutz, "Mechanical Engineers Handbook", A. Ravi Ravindran and G. V. Reklaitis (Eds.), $4^{\text {th }}$ edition, Volume 2: Design1, 2015, p. 97-124.

36. R. K. Roy, "Design of Experiments Using the Taguchi Approach: 16 Steps to Product and Process Improvement", John Wily \&Sons, Inc., New York, 2001.

37. H. Oktem, T. Erzurumlu and I. Uzman, Materials and Design., 2007, 28, 1271-1278.

38. S. Mohapatra and G. B. Nando, Ind. Eng. Chem. Research., 2013, 52, 5951-5957.

39. Y. Ma, H. Hu, D. Northwood and X. Nie, J. Mater. Process. Techn., 2007, 182, 58-64.

40. T. Erzurumlu and B. Ozcelik, Materials and Design., 2006, 27, 853-861. 
